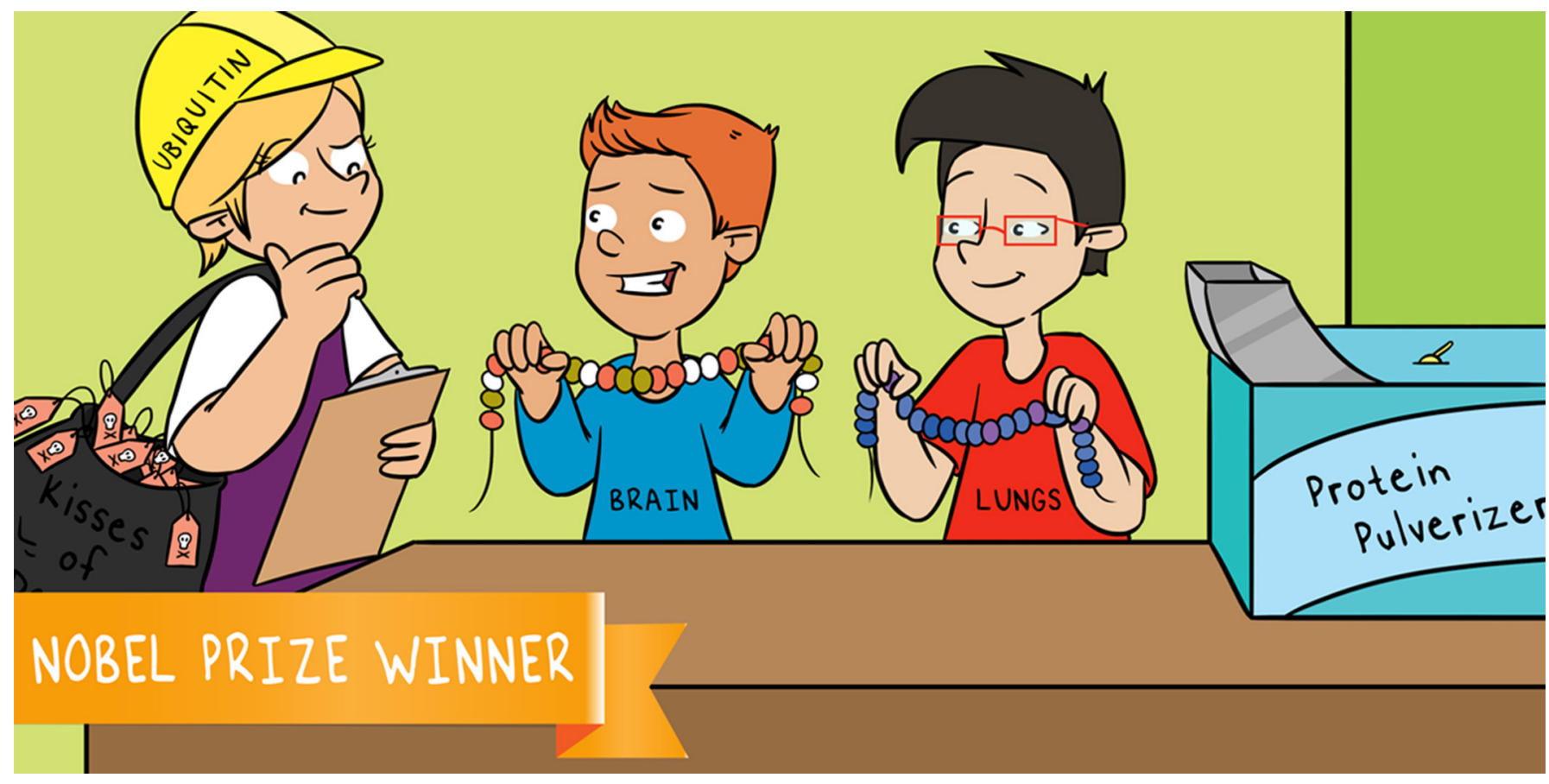

\title{
TARGETED DEGRADATION OF PROTEINS - THE UBIQUITIN SYSTEM
}

\section{Aaron Ciechanover*}

The Rappaport-Technion Integrated Cancer Center (R-TICC), The Ruth and Bruce Rappaport Faculty of Medicine, Technion, Israel Institute of Technology, Haifa, Israel

YOUNG REVIEWERS HEBREW UNIVERSITY SECONDARY SCHOOL AGE: 14
Proteins are the engines of all forms of life, for humans and for all the plant and animal kingdoms. Proteins are used both to build organs (such as bones, muscles, and skin) and to perform bodily functions. These functions range from digestion (processing food and converting it into energy), to enabling movement and sensation (sight and hearing), to protecting the body from foreign invaders with our antibodies, which are also proteins. What are proteins? They can be compared to words in a language that contains letters. In the Hebrew alphabet, there are 26 letters out of which countless words can be composed. But when we write, we use just a fraction of these infinite options, with the average number of letters in a word ranging between 3 and 8 . The biological "protein alphabet" is comprised of 20 "letters" called amino acids, which are the building blocks of the proteins that make up the body. Proteins are chains of amino acid, linked together in a specific order governed by the DNA. Unlike the words of a spoken language, the average protein consists of hundreds of amino acids. The extensive length of proteins and the 


\section{PROTEIN}

An organic molecule present in all organisms, including viruses. A protein is a chain that can be composed of 20 different building blocks called amino acids. This chain has a primary structure (the amino acid sequence), a secondary structure (the arrangement of the acids in helices and sheets), a tertiary structure (the three dimensional arrangement of the structure), and a quaternary structure (the structure of the different subunits in a complex). Proteins are central components in many processes in the body, such as: food digestion, energy production, structure (bones), movement (muscles), cell division, sensory (such as sight) and defense from foreign invaders (antibodies). Proteins are very sensitive to environmental conditions like temperature and oxygen, and are constantly being damaged, which is why they are in a constant turnover of formation and degradation. chemical composition of the amino acids make proteins sensitive to many factors, such as high temperatures, radiation, and chemicals. All these factors damage proteins and alter their fragile structures, negatively affecting how they function. When proteins are damaged or when they finish performing their functions and are no longer needed, the body breaks them down. With my doctoral adviser, Prof. Avram Hershko, and our research collaborator, Prof. Irwin Rose from the Fox Chase Cancer Center in Philadelphia, we discovered the mechanism responsible for targeted degradation of proteins in cells. This degradation can recognize damaged proteins or proteins that are not needed anymore, while leaving intact the "healthy," functional ones. This mechanism is called the ubiquitin system after its principal protein, ubiquitin, which was the first protein we discovered in the system. Ubiquitin's role is to tag undesirable proteins so that the cell's "grinder" can recognize them and break them down, enabling the cell to function normally. In this article, we will explain the story of proteins and the ubiquitin system that we discovered in a study that earned us, among other prizes, the Nobel Prize in Chemistry in 2004.

Professor Ciechanover won the Nobel Prize in Chemistry in $\mathbf{2 0 0 4}$ for the discovery of the ubiquitin system, which is responsible for protein degradation in the body's cells.

Interviewed and co-written by Noa Segev, graduate of the Grand Technion Energy Program, Technion, Israel Institute of Technology, Haifa, Israel.

\section{PROTEINS: WHAT ARE THEY AND WHAT FUNCTIONS DO THEY PERFORM IN THE BODY?}

\section{Twisting Chains of Beads}

Proteins are essential biological molecules that are made from building blocks called amino acids. There are 20 different amino acids that comprise all the proteins in our bodies (and in all other plants and animals). Think of amino acids as beads that connect to each other to form a chain. This chain is the most basic structure of a protein, and it is called the primary structure (Figure 1A). When this chain begins to twist and turn, more complex structures are created (Figure 1B). The most common are a spiral called an alpha $(\alpha)$ helix, or a pane-like structure called a beta $(\beta)$ sheet. The tertiary structure (Figure $1 \mathrm{C}$ ) is a three-dimensional structure formed by the folded secondary structures, and it creates a protein that can perform a variety of functions in the cell. The fourth and final structure is called the quaternary structure (Figure 1D), and it is formed from at least two proteins that interact with each other. 
Figure 1

The structure of a protein. Proteins are made from 20 "beads" called amino acids. When the amino acids join to each other, they create a chain called the primary structure (A). The primary structure can twist and turn and take on more complex forms, called secondary, tertiary, and quaternary structures ( $B-D$, respectively). The secondary structure comes in two main forms - the alpha helix and the beta sheet $(B)$. The tertiary structure arises from the folding of the secondary structure (C). The quaternary structure, which is formed only in certain proteins, is made up of at least two proteins that interact with each other (D) (Image credit: Wikipedia)

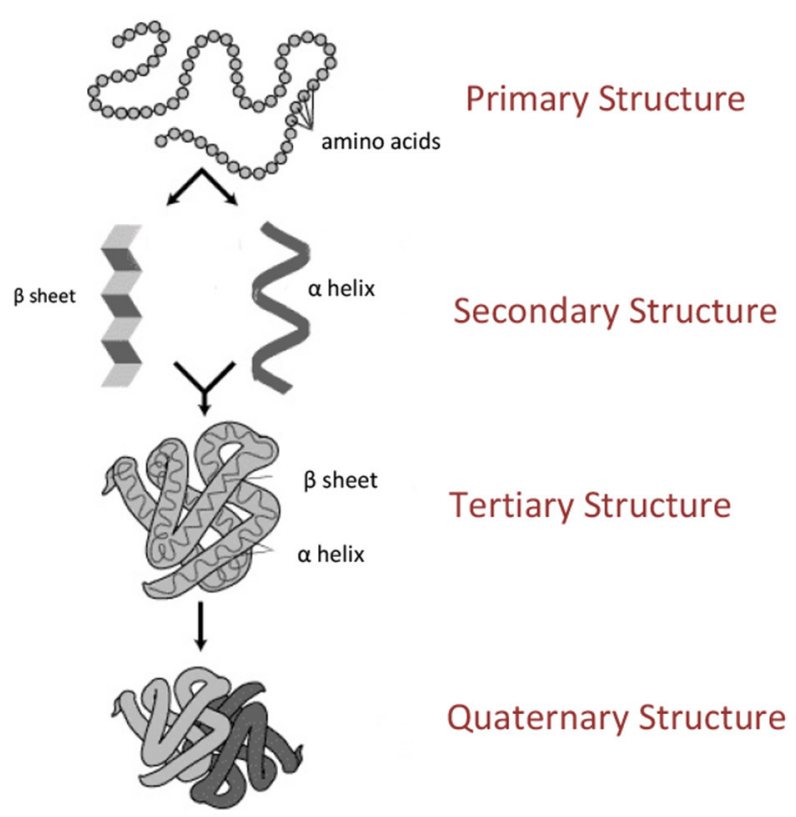

Figure 1

It is important to mention that when we consume proteins through foods, like eggs, cheese, or meat, it is not possible to absorb them in their chain form, since in this state they are like foreign substances that invade the body, and they may trigger an immune response. Instead, the digestive system breaks down the proteins from their complex, chain form into their amino acids, and these are absorbed by the body. The body can use these absorbed amino acids to create any new proteins that it needs.

\section{The Protein Symphony Within Us}

There are about 25,000 different proteins in the human body, with millions of copies in each of the body's cells. Some proteins, which are essential for basic functions, such as energy production, are found in every single cell, while others are only found in specific tissues, like light receptors in the eye. These proteins play together in a wondrous symphony, the symphony of life. The beauty of this orchestra is that proteins do not even need a conductor; each protein knows exactly what it must do at any given moment. Most of these functions are automatic: the beating heart, the exchange of gases in the lungs, filtration in the kidneys, digestion in the digestive tract, even posture and walking. We actively think about only a small fraction of the things we do, like thinking, talking, and writing.

Proteins carry out a variety of diverse functions in the body (Figure 2); here are a few examples. To move, the body must use muscles. But what makes our muscles move? Two proteins called actin and myosin, which are found in our muscle cells. You can think of actin and myosin as cogwheels that lock into and move against each other. Myosin's "head" can move toward actin, and once it binds to the actin 
Figure 2

Examples of functions of proteins in the body. Clockwise from the left: a light receptor in the eye called rhodopsin enables sight in low-light conditions; in muscle cells, actin and myosin enable muscles to contract; a hormone called insulin, secreted by the pancreas, regulates the sugar levels in the blood; immune system proteins called an antibodies help neutralize foreign invaders; hemoglobin in red blood cells carries oxygen to the cells; rubisco plays a role in the conversion of sunlight into energy in the form of sugars in plants and other organisms; ferritin binds iron in cells so that it can be stored (a ferritin deficiency may lead to anemia); spider webs are made out of structural proteins that are secreted by the spider.

IMMUNE SYSTEM

The body's defense system against harmful invaders like viruses and bacteria.

\section{ANTIBODY}

A protein in the immune system, whose function is to help neutralize harmful invaders.

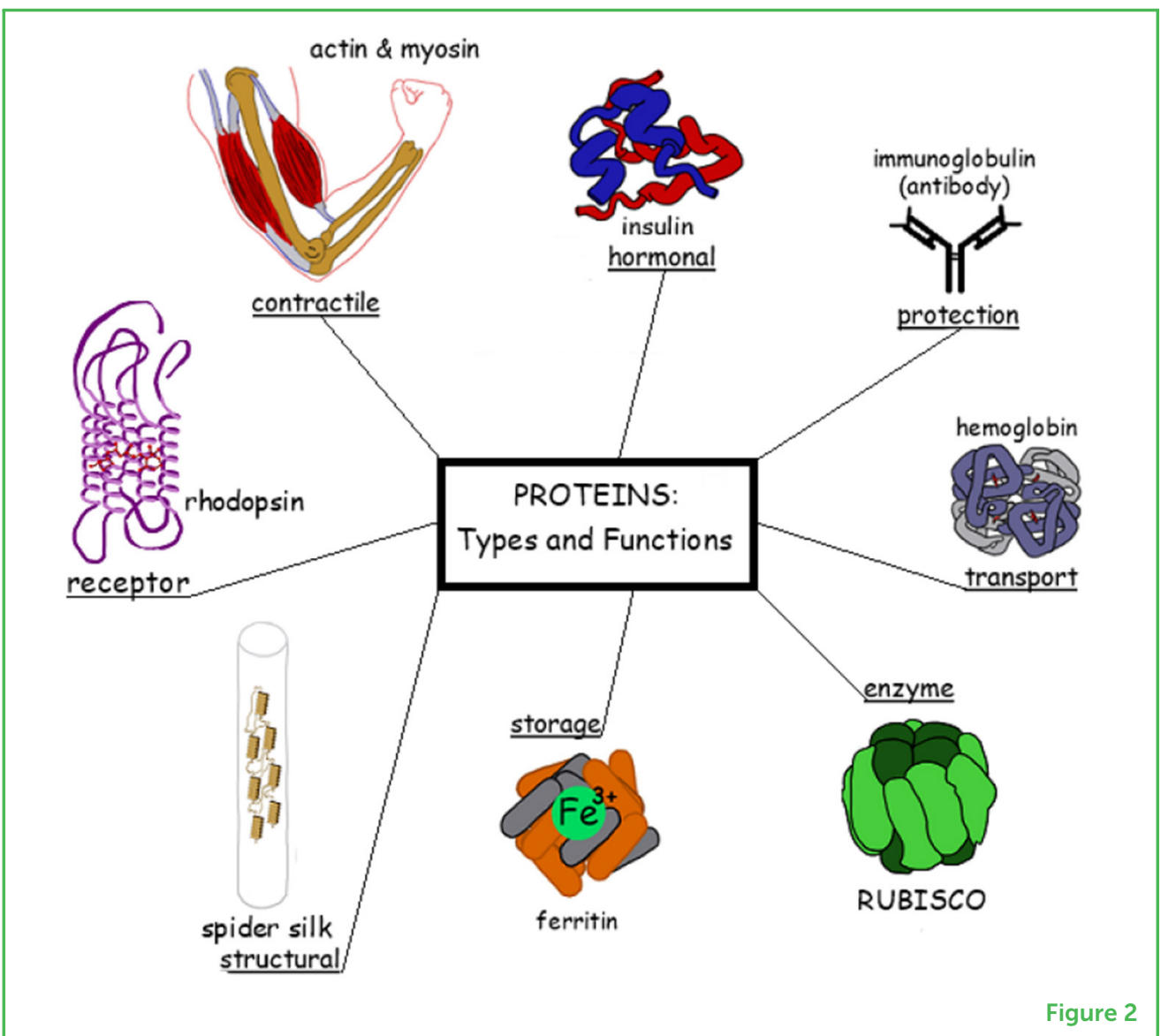

filament it pulls it, while simultaneously pulling another adjacent actin filament toward it. The pulling of two actin filaments toward each other (occurring simultaneously by many myosin heads in a muscle) is what causes muscles to contract (a demonstration of the action of myosin and actin can be seen in this clip).

Let us look at a different example, breathing. Do you know why we breathe? To create energy. We absorb oxygen from the air into our tissues so that we can make energy for our cells to use. In the process of making this energy, $\mathrm{CO}_{2}$ gas is formed as a waste product and must be expelled from the body by the lungs. Both the transfer of oxygen from the lungs to the cells (during inhalation) and the transfer of $\mathrm{CO}_{2}$ from the cells to the lungs (during exhalation) are mediated by a protein called hemoglobin. Hemoglobin is found in red blood cells and gives blood its red color and that can be found in red blood cells; see Figure 2, right).

If we look at the body's immune system, which protects us from diseases and infections, we will also find proteins, in this case called antibodies. Antibody proteins attach themselves to invading viruses or bacteria and cause the invader to be neutralized and destroyed (Figure 2 , top right corner). One way to create antibodies is by administering a vaccine against diseases, such as flu, polio, or measles. Vaccines can 
Figure 3

Proteins found in foods are damaged at room temperature and higher. Milk and meat spoil very quickly out of the refrigerator, for the same reasons that you cannot "uncook" a hardboiled egg. At room temperature and higher, proteins lose their organized structure, which gives them their proper function, and they become "disorganized." This process of altering a protein's structure is called denaturation, and it may occur due to heat, or exposure to oxygen or radiation (Image credit: istockphoto.com/ fcafotodigital).

\section{PROTEIN}

\section{DENATURATION}

A process in which the three-dimensional structure of a protein is altered as a result of high temperature, for example. Denaturation damages the proper function of the protein

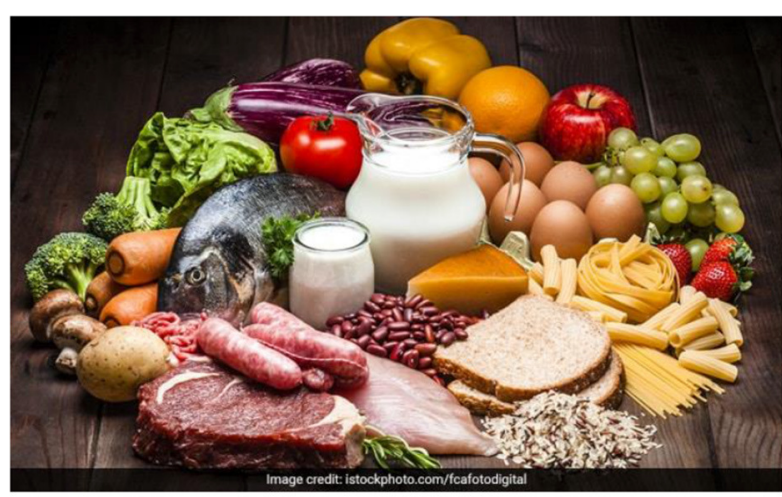

consist of a dead or weakened virus that cannot cause the disease, but can still trigger the immune system to create antibodies against it. After vaccination, if viruses or bacteria of the same type invade the body, the body will be ready to take them on and destroy them, using the antibodies that were formed against the vaccine. This is especially important today, since we hope that antibodies will protect us from SARS-CoV-2, the coronavirus that causes COVID-19, whether they are formed after we get sick (heaven forbid) or after we are vaccinated. Further examples of protein functions can be found in Figure 2.

\section{Sensitive Proteins: Why Cannot a Cooked Egg Be Returned to Its Liquid State?}

As described, the body has many types of proteins that perform a variety of important functions. The trouble is that proteins are extremely sensitive and are easily damaged. For example, if you leave milk or fresh meat out of the refrigerator, they will spoil very quickly (Figure 3). Similarly, when an egg is cooked, the heat transforms the proteins from a liquid state to a solid one and it is impossible to return the egg back to its original state, no matter what you do. The same goes for a fried egg. Even if you were to piece the broken shell back together, put everything back into the shell, and cool it in the refrigerator, the egg would not return to its original, liquid state.

Why does this happen? Because proteins in foods get ruined at room temperature and higher, such as temperatures used in cooking. Proteins, as we have explained, fold into complex structures, such as spherical coils. When proteins are heated, the relatively weak chemical bonds that hold their three-dimensional structures together become weaker, causing the proteins to lose their shape and become "disorganized." Think of a ball of yarn that has been unwound then tangled. This disorganization makes proteins lose their functions. This process is called denaturation. Denaturation can also be caused by radiation from radioactive materials or ultra-violet radiation from the sun. Another cause of protein denaturation is chemical changes to the amino acids, like those caused by the oxygen in the air. The damage 
to protein structure from denaturing factors causes the protein to stop functioning as it should.

In addition to damaged proteins, there are many proteins whose function is needed only during specific times, like during cell division. This is one of the steps in the lifecycle of the cell, and it occurs, when all is well, at a specific point every so often. As a result of the division two cells are formed. Also, when one cell dies the remaining cell will divide again to make up for the one that was lost. This division is mediated by certain proteins ("division accelerators"), and once division has occurred they are no longer needed. They are degraded and in their place "division inhibitors" are created and so forth. If, for instance, these division accelerators were to remain in the cell, the cell will continue to divide many times in an uncontrolled manner, which can lead to diseases, such as cancer.

For all the above reasons, the proteins in the human body can be damaged as well. The body's high temperature (roughly $37^{\circ} \mathrm{C}$ ), exposure to the oxygen in the air, radiation and chemicals are all causes of harm to the proteins that make up our body.

An important point to mention is that life at $37^{\circ} \mathrm{C}$ is necessary to optimize all the chemical reactions whose purpose is one- maintaining life. No one can deny the need for oxygen, either. Thus, perhaps paradoxically, the two most important factors for maintaining life were discovered to be harmful to the structure of proteins. Therefore, evolution made sure to develop mechanisms for fixing and quality checking to deal with this damage, neutralize it and enable life. These mechanisms are an intrinsic part of life itself. This is not like a traffic accident and then repairing the subsequent damage, since accidents may or may not occur. Rather, these are coupled processes, the price we pay for the pleasure of being alive, which I would term destruction for the sake of construction. The body has many mechanisms for quality control that protect all its elements including the genetic material, the DNA, from damage. There are even a number of different mechanisms for protecting each element, a sort of safety net, evidence of how important this protection from the environment is. We will discuss here just one of these systems, the one that degrades damaged or unneeded proteins, to avoid the damage caused by their accumulation.

\section{How Does the Body Deal With Damaged Proteins or Those That Completed Their Function and Are Not Needed Anymore?}

If so, how does the body deal with damaged proteins and those whose function has come to an end and are no longer needed, and whose continued function and $\backslash$ or accumulation may cause harm? It breaks them down into their most basic elements-the amino acids. The rate of degradation is astounding: about $6-7 \%$ of the proteins in the body are degraded every single day and are very accurately replaced by new 
UBIQUITIN

A protein that tags other proteins for degradation. ones created in their wake (by the DNA and RNA systems that exist in every cell in our body). This means that in the short time of a month or two all the proteins in our body-beside a small number of unusually stable ones-are replaced. Note that this is an average number. There are some proteins that have very short lives and are replaced a few times an hour, and there are others, like hemoglobin, that are long-lived and are replaced only once every few months. A fascinating question that arises is, if all the proteins in your body are different from those of 2 months ago, are you still the same person that you were before? How are memories, talents, and emotions, the "software" that makes us human, maintained, while our entire "hardware" is replaced? Another question is, if we are constantly regenerating, why do we age? These captivating questions are still unanswered. What we do know is how the cellular system responsible for the specific degradation of damaged or unneeded proteins functions. This system is called the ubiquitin system [1].

It is worth mentioning here that there are some diseases, some of which are severe, that are linked to the malfunctioning of the protein degradation systems in the body. In Alzheimer's disease, for example, certain proteins that should degrade but fail to do so, accumulate in the brain, which ultimately leads to brain shrinkage and the loss of cognitive functions, memory among them. A similar situation occurs in Parkinson's disease. Malignancies too can sometimes be caused by mutations in genes, the code for functional regulatory proteins. These mutations transform them into oncogenes, genes that cause cancer (oncos-swelling in Greek). Understanding the mechanisms for protein degradation in the body may therefore enable us to develop drugs and to treat conditions like Alzheimer's disease by restoring the proper function of the protein degradation system. It is also possible to deliberately damage the protein degradation system in cells to treat some diseases. An example of such a disease is multiple myeloma. This condition is caused by the uncontrolled cell division of the cells in the bone marrow that create antibodies. This accelerated division leads to damage to bone structure, causing breaks, and also to suppression of the division of other cells in bone marrow, such as white and red blood cells. This can cause breathing difficulties because of the reduced ability of the blood to bind oxygen, and to infections due to the lack of white blood cells to fight them. By interfering with the protein degradation systems in these cells and purposefully preventing the degradation of antibodies, proteins can build up and kill the cells that produce them, thus slowing down the disease. In a later section we will refer in more detail to the multiple myeloma disease and its medicinal treatment.

\section{A SYSTEM FOR PROTEIN DEGRADATION Ubiquitin: The "Kiss of Death" for Proteins}

As we previously mentioned, there are several reasons for the degradation of proteins in the body. The first reason is for quality 
Figure 4

The ubiquitin system for tagging proteins for degradation. The ubiquitin system is a complex system whose purpose is to tag proteins meant for degradation ("Target" protein in the center) The system is comprised of three different types of proteins: two carrier proteins, E1 and E2 (above, in green and orange, respectively) whose job is to activate and later carry the ubiquitin protein, and its ligase (E3, left, in pink) whose job is to hold the target protein while ubiquitin binds with the latter. Once the ubiquitin has been activated by $\mathrm{E} 1$ it is transferred to E2 and binds to the target protein that is "harnessed" to E3 (sometimes it can be transferred first to E3 and only then to the target protein). At first a single ubiquitin molecule is attached to the target protein, and later more ubiquitin molecules bind to it and to each other, head to tail, to create a polyubiquitin chain (UB, dark green top right). This tagging of the target protein by the polyubiquitin chain is what signals to the cell that it must now recruit the "grinder" to degrade the protein. This "kiss of death" - the polyubiquitin chain-can be equated to those that are sentenced to death in the United States and that are dressed in a different uniform, to mark them in advance.

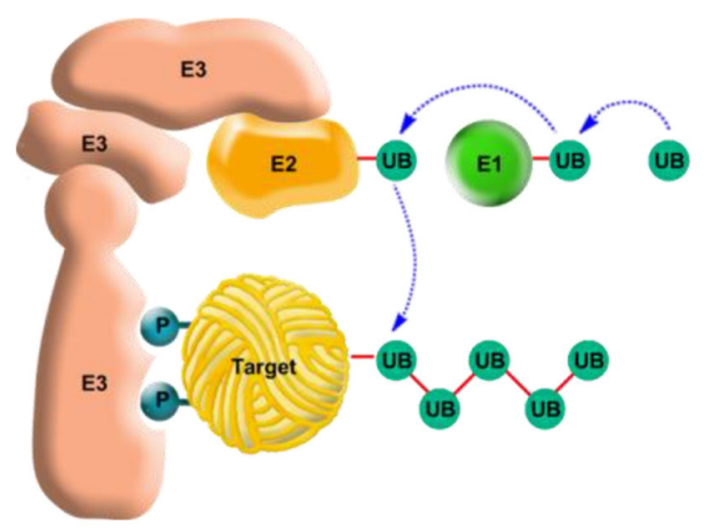

Figure 4

control, in other words degrading abnormal proteins, such as those that were harmed by the denaturation that was mentioned above. Another reason is for process regulation, in other words accelerating or inhibiting processes that are protein-dependent, such as cell division. A third reason is for the proper differentiation of tissues. As a part of embryo development, cells need to differentiate in order to build the different tissues and organs of the body: brain cells, pancreatic cells, muscle cells, and so on. Each tissue is constructed from proteins needed for its function only, and not from the sum of all proteins in the body. Thus, as part of the cell differentiation process it is necessary to degrade proteins, which allows for the correct differentiation of cells and proteins into the appropriate tissue.

How can the body distinguish between dysfunctional or unnecessary proteins and functional proteins whose continued presence is necessary? And once the proteins that need to be degraded are recognized, how are they actually broken down? It turns out that all the proteins meant for degradation are recognized by the cell and undergo a tagging that we call the "kiss of death." How are they tagged? One speculation is that the tagging system might be able to identify the parts of the protein that are exposed if the protein denatures-parts that are not normally exposed. Another possibility is that, as a protein begins to denature, further changes happen to it, such as the addition of a phosphate molecule, and it is this addition that attracts the "kiss of death." This "kiss" is carried out by a protein called ubiquitin. During the first step, the protein that needs to be tagged, the one meant for degradation (Target protein in Figure 4, yellow) associates itself with one of a thousand proteins that are called ubiquitin ligases (since they ligate, or join, ubiquitin to the target protein) and that are called E3 (Figure 4, pink). This binding between the target and ubiquitin ligase is very specific, like a lock and a key. This connection between the "victim" and the ligases fixes the protein in its place, like a car mount for a cellphone, so that it will be "comfortable" for ubiquitin to bind to it. 
Figure 4

Yet, just as those prisoners have the right of appeal, also in nature there is a possibility of saving the target protein: if the protein has regained its natural form, folded correctly and is prepared to function once again then ubiquitin remover proteins can separate the chain from the former target and disassemble it to single ubiquitin molecules for reuse in the cell where they will attach to other proteins needed for degradation, similar to the process of pardoning those sentenced to death (see also Figure 5).

\section{PROTEIN}

\section{ACTIVATION}

Moving the protein from a state in which it cannot carry out a certain function (this state is called "dormant") to a state in which it is capable of carrying out that certain function (it can now be called "active")

\section{ENZYME}

A protein whose function is to speed up chemical reactions by lowering the amount of energy necessary for the reaction.
Before ubiquitin binds to the target protein and "kisses" it, it must go through two stages of activation. This activation can be thought of as activating an app on a cellphone-the app is always installed, but until you open it, it is not active (and there is no reason for it to be constantly active. The activation of ubiquitin is accomplished by E1-a single protein known also as an enzyme that activates ubiquitin (Figure 4, top right). Once activated, the ubiquitin is carried by one of the fifty E2 proteins to the bound target protein. The activated ubiquitin attaches itself to the target protein (Figure 4, bottom) and then additional ubiquitin proteins connect to it, to form the polyubiquitin chain that constitutes the "kiss of death" that signals the cell to degrade the target protein.

Once the target protein is tagged with a polyubiquitin chain, this chain binds an enzyme (which is also a type of protein) called the proteasome (Figure 5), whose purpose is to degrade the protein. The proteasome can be thought of as a "grinder" that grinds up the protein and disintegrates it into its basic components-the amino acids. At first, the polyubiquitin chain serves as glue to adhere the target protein fated for degradation to the "blender" (Figure 5, right). Next, the target protein is unfolded by other enzymes into a long chain (Figure 5, center), and fed into the proteasome. While passing through the proteasome it is degraded into its basic components (Figure 5, left) which the cell can recycle and use to build new proteins.

We have seen that, for a protein to be degraded in the cell by the ubiquitin system, there are two main stages: (A) The creation of the polyubiquitin chain that is attached to the target protein; and (B) The recruitment of the proteasome followed by the degradation of the target protein and recycling of its components, the amino acids, to build new proteins. The ubiquitin molecules are also recycled, so they can tag other proteins for degradation. The wonderful thing about this system is that each protein destined for degradation is like a needle in a haystack; it is one among millions of other proteins that are needed and that the body must not break down. The beauty of this system is that it can recognize this needle in a haystack, using ubiquitin as a tag, and perform targeted degradation only of the damaged/unneeded proteins.

This targeted mode of action is unique to the ubiquitin system in relation to other biological processes that degrade proteins and that do so indiscriminately. These systems, like the lysosome and autophagy, "swallow" everything around them and degrade all the swallowed protein without discrimination. This too serves a purpose, such as providing building blocks and energy during starvation. In such a time of stress, it does not matter which proteins are degraded. The body needs building blocks and energy, and any protein can serve this purpose. The function of the ubiquitin system is different; it can identify and guide the degradation only of proteins that must be degraded, and not the other proteins that are critical for most of our functions. As the 
Figure 5

Degradation of ubiquitin-tagged target protein. The target protein is degraded by the "blender" or "garburator," a protein complex called the proteasome (blue body). (Right) The target protein ("Target," yellow), fated for degradation and tagged by the chain of activated ubiquitin proteins (UB, see Figure 4, above), is attached via this chain to the proteasome. (Middle) Other enzymes unfold the target protein (yellow open coil, above) and feed it into the proteasome, while ubiquitin remover proteins release the ubiquitin which is recycled. (Left) The proteasome complex degrades the unfolded target protein into its fundamental unitssmall chains of amino acids (called peptides) that are later broken down into single amino acids (yellow fragments, below)

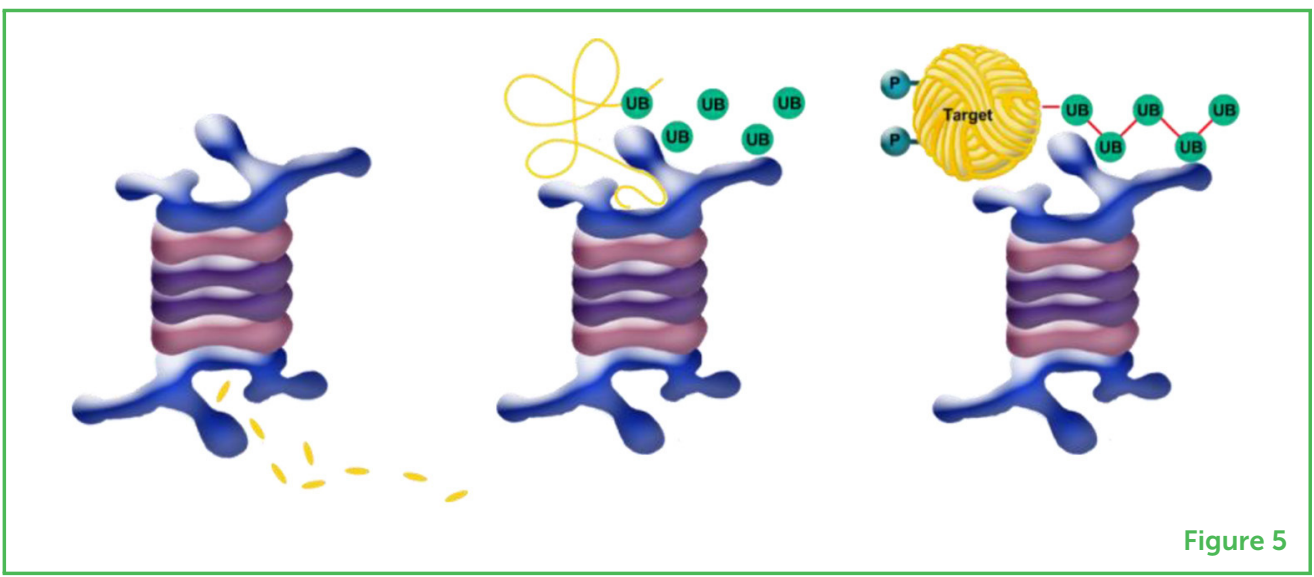

wisest of men, the author of Ecclesiastes, said, "To everything there is a season, and a time to every purpose under heaven: A time to be born, and a time to die; a time to plant, and a time to pluck up that which is planted; a time to kill, and a time to heal; a time to break down, and a time to build up; a time to weep, and a time to laugh; a time to mourn, and a time to dance."

\section{Drugs Based on the Ubiquitin System}

Once we understood how the ubiquitin system works, the fact that its disruption can lead to disease, and the fact that this system can be regulated, it was time to develop medical applications based on the ubiquitin system. As we have seen, proteins carry out many important functions in the human body, and their normal functions are dependent on the proper functioning of the ubiquitin system. Yet there are cases where the ubiquitin system malfunctions, like when it is overloaded (when too many proteins need to be degraded at once) or when the function of one of its elements is disrupted, such as is caused by a mutation in one of the E2 (one of the ubiquitin carrier proteins) or E3 enzymes (one of the ubiquitin ligase proteins, see Figure 4). When the ubiquitin system is not operating properly, proteins may be degraded either too much or not enough, and then a disease may develop. Cancer is an important example. The cells in our bodies have different rates of division. Some of them divide once every few days (the epithelial cells that coat the digestive system or bone marrow cells, which are the blood "factory"). Others, such as brain, muscle, and fat cells, do not divide at all. Still others divide very slowly, including bone and cartilage cells. In cancer, the cells of the affected tissue divide rapidly and uncontrollably and form a tumor. One of the causes of cancer is the malfunction of the ubiquitin system. This can happen when the body degrades too many proteins that repress cell division, or when it fails to degrade proteins that encourage cell division. In these instances, cells may increase their rate of division uncontrollably and become cancerous. It is not necessarily a result of a failure in the ubiquitin system. Cancer is "sneaky" and can create proteins "on purpose" which encourage cell division that the ubiquitin system is not 
familiar with and cannot recognize them as proteins that need to be degraded. It is these proteins that initiate the cancerous process.

Today, there are two families of drugs in use to treat cancers of the blood, especially cancer of the lymphocytes, the cells that produce antibodies (multiple myeloma). One family of drugs is called proteasome inhibitors. They inhibit the degradation of the antibodies that are formed in the cancer cells and should be broken down; this buildup and retention causes cell stress that kills the cancerous cell. It is interesting to note that this mode of action is different than that of most anti-cancer treatments, like chemotherapy, and this difference means that proteasome inhibitors can be given along with chemotherapy drugs, to make chemotherapy more effective. Drugs in the second family contain a molecule that connects "by force" the cancer-causing proteins to the ubiquitin ligase, which otherwise would not have bound them. These are "double-headed" proteins, in which one head binds to the cancer-causing protein and the other to the ubiquitin ligase. Ubiquitin ligase then attaches ubiquitin to the cancer-causing protein, which results in its degradation by the proteasome. These two types of drugs have dramatically increased the odds of recovery from multiple myeloma. Previously, this disease killed people painfully within 2 years of diagnosis. Now, multiple myeloma is curable in some patients, while others survive longer, with improved quality of life. Therefore, our understanding of the ubiquitin system has contributed, and continues to contribute, to the development of life-saving drugs.

Here is a personal story that touches on the saving of a life and also to my career, that changed direction from medicine to research. When we arrived in Sweden to receive the Nobel Prize in December of 2004, the Israeli ambassador threw us a party, along with the leaders of the local Jewish community. This party celebrated both the Nobel Prize and the holiday of Chanukah, which took place at the same time. The ambassador prepared a "gift" for us. This gift was not a box wrapped with paper and a colorful bow, but a Swedish man. Up until a few weeks before then, this man had been on his deathbed in a hospital in Stockholm, suffering from multiple myeloma. His last resort was a drug that was still experimental, a proteasome inhibitor called Velcade ${ }^{\circledR}$ that had been developed in the United States based on the function of the ubiquitin system we had discovered. In Figure 6, you can see an example of the state of the bone marrow (tissue that is the "factory" that makes all the blood cells and that can be found mostly in the core of vertebrae and long bones of the body, the thigh, and arm bones) of a patient before and after treatment with Velcade ${ }^{\circledR}$.

A few days after receiving the drug intravenously, the patient was able to get up and return to living a normal life. That moment, in which a person approached us, passionately embraced us with tears in his eyes, and thanked us for saving his life (albeit indirectly) was a very emotional moment for me, a moment of coming full-circle. Although 
Figure 6

Bone marrow from a multiple myeloma patient before and after Velcade ${ }^{\circledR}$. In multiple myeloma malignancy, plasma cells that normally generate antibodies undergo a transformation and begin to multiply uncontrollably in the bone marrow, the "factory" that creates all the types of blood cells. (Left) The bone marrow of a patient prior to treatment with Velcade ${ }^{\circledR}$, which is a drug that inhibits the proteasome. The marrow is flooded with plasma cells that have multiplied uncontrollably. It contains $41 \%$ cancerous plasma cells. (Right) Bone marrow from the same patient after treatment with Velcade ${ }^{\circledR}$. It now contains only $1 \%$ cancerous plasma cells This photo was given to Prof. Ciechanover courtesy of Millennium Pharnaceuticals.
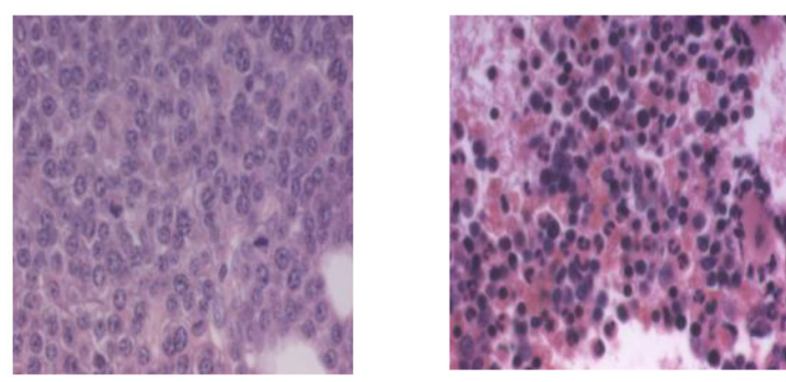

Figure 6

I did not continue my original career path as a doctor, I still ended up affecting lives through my research, perhaps more profoundly than I would have had I continued to practice medicine.

\section{RECOMMENDATIONS FOR YOUNG READERS}

If you are uncertain about what you want to be when you grow up, I would recommend you do this: pursue what you feel that you are very good at and that you love doing. Often, these things go together: if you really love doing something, and it is your biggest hobby, then you will also be good at it. You will devote yourself to it and study it, and you will learn how to deal with the obstacles along the way. If you truly love something, you will realize that there are no failures but rather lessons to be learned, and progress toward the success that will surely come.

When people ask me about the secret of my success, I say that I was wise to identify that maybe I was not good enough at my first occupation (medicine), but mostly that I did not love it enough. I realized that I needed to move to another occupation. I knew that I was not good at mathematics, so I did not even attempt a career that required significant knowledge in that field. I actually liked medicine, but once I was deep in it I realized that over the years in this profession (which is a fascinating one), I would repeat myself over and over again, diagnose and treat the same diseases. Although it was important and interesting, I thought I was more suited for innovation. I chose research and knew right away that this is my hobby; it is what I love to do. I also knew to choose a young and inexperienced supervisor who made a great name for himself, Avram Hershko, with whom I came a long way (and together we were awarded the Nobel Prize). He had only just completed his post-doctoral fellowship, and I purposefully chose him because he offered me an adventurous path into the unknown. He had a hypothesis that was a starting point in a different direction than the conventional one. Of course, we needed luck, too. When I am asked, "why did you decide to work on ubiquitin?" I answer that I did not, but rather I decided to work on the biological problem of how proteins are degraded. Working on this biological question 
using biochemical techniques is what revealed ubiquitin to us. Later, techniques for sequencing the human genome revealed the full extent of the ubiquitin system and its important function in regulating many bodily processes. Eventually, the importance of the ubiquitin mechanism in the development of life-saving drugs was discovered, but even now we are only at the beginning of the road.

I have been in this field for almost five decades, but every day is like the first day for me. I am surrounded by young and creative people who enrich me with their innovative ideas, and I contribute to them from my experience. The meeting between innovation and experience is fascinating and develops new ideas that are often correct. For me, the love of the profession is no different from any other love: loving one's parents, close friends, or one's partner. So, my wish is that you find that professional love, and that it brings you success. This love need not be in science, it can be in any field: art, music, engineering, medicine, law, or architecture. What is important is that you feel that what you are doing fits you like a glove. This will ensure your success and your contribution to others, and will keep you interested and curious for many years to come.

To those of you who do choose science as a career, I have further advice: tell a story. If you want to have an impact, you need to be consistent and construct a story. As soon as you have found an interesting beginning to a potential story, persist, develop it, and do not constantly jump around from subject to subject. It is like being every day someplace else-people would not recognize you and would not be able to identify your special story. Prof. Hershko and I are each identified as "Mr. Ubiquitin." Ubiquitin is our story, and that is what enabled us to open up a whole new field of research, to pave new trails in science, and to generate knowledge that ultimately led to saving lives. If I had abandoned the story after publishing the first paper, these things would never have been possible. Remember to be patient, and remember that our goal in science is not to become professors and especially not to receive awards; these will follow if you succeed. Our goal as scientists is to uncover the secrets of nature and maybe also to use them for the benefit of mankind. The true test of science comes when someone repeats your experiment in Buenos Aires, New York, or Paris without you even knowing it, and then someone else does a follow-up experiment, and then a follow-up to that, and gradually a whole new story of innovation is revealed. Today, there are many thousands of people worldwide who are working with a system that was first discovered in the early 1980s, in a small lab in the Technion in Haifa. Big drug companies manufacture life-saving drugs, many millions of people have benefited, and more will continue to benefit when their lives are saved, and their quality of life is improved. That is the most enjoyable reward that anyone can dream of. 


\section{Additional Material}

1. The Nobel Prize in Chemistry 2004-Aaron Ciechanover

\section{ACKNOWLEDGMENTS}

I would like to thank Noa Segev, a graduate of the Nancy and Stephen Grand Technion Energy program (GTEP), Israel for the interview that was the basis for this article, and jointly writing it. Thanks also to Prof. Michael Brandies for the help in answering the questions of the young reviewers.

\section{REFERENCES}

1. Hershko, A., and Ciechanover, A. 1992. The ubiquitin system for protein degradation. Annu. Rev. Biochem. 61:761-807.

doi: 10.1146/annurev.bi.61.070192.003553

SUBMITTED: 01 February 2021; ACCEPTED: 11 March 2021;

PUBLISHED ONLINE: 07 September 2021.

EDITOR: Idan Segev, Hebrew University of Jerusalem, Israel

CITATION: Ciechanover A (2021) Targeted Degradation of Proteins - The Ubiquitin System. Front. Young Minds 9:662619. doi: 10.3389/frym.2021.662619

CONFLICT OF INTEREST: The author declares that the research was conducted in the absence of any commercial or financial relationships that could be construed as a potential conflict of interest.

COPYRIGHT @ 2021 Ciechanover. This is an open-access article distributed under the terms of the Creative Commons Attribution License (CC BY). The use, distribution or reproduction in other forums is permitted, provided the original author(s) and the copyright owner(s) are credited and that the original publication in this journal is cited, in accordance with accepted academic practice. No use, distribution or reproduction is permitted which does not comply with these terms.

\section{YOUNG REVIEWERS}

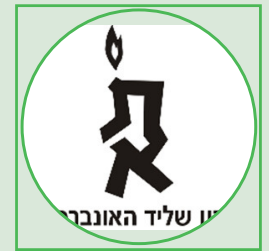

\section{HEBREW UNIVERSITY SECONDARY SCHOOL, AGE: 14}

We are a group of students in eighth grade at the Hebrew University High School in Jerusalem, we study in the biology honors program, meaning we chose to study biology in depth and breadth. This year (2019-2020) we are learning about the cell, its components and the processes that occur in it. 


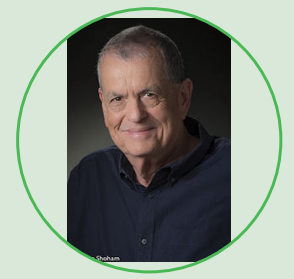

\section{AUTHOR}

\section{AARON CIECHANOVER}

Professor in the Technion Integrated Cancer Center in the Faculty of Medicine, recipient of the Nobel Prize in chemistry in 2004 for the discovery of the ubiquitin system for protein degradation in the cell. Professor Ciechanover is a doctor by training, a graduate of the Hadassah medical school and of Hebrew University of Jerusalem (1972) as part of the academic army service (atuda). After graduating, he served in the Israel Defense Forces as a combat doctor, then he joined the department of biochemistry in the faculty of medicine in the Technion, where he conducted his Ph.D. research under the supervision of Professor Avram Hershko. His research from 1976 to 1981 was an attempt to understand how cellular proteins are degraded in a specific manner; in other words, how the cell gets rid of only the proteins that need to be destroyed at that point in time, like those that have been damaged. This research resulted in the award of the 2004 Nobel Prize in Chemistry to Professor Ciechanover, along with Professor Hershko from the Technion and Professor Irwin Rose from the Fox Chase Cancer Center in Philadelphia, USA. In the same year, Professor Ciechanover was also chosen to be a member of the Israel Academy of Sciences and Humanities in the field of biochemistry. Before receiving the Nobel Prize, Professor Ciechanover was awarded other important prizes, such as the Albert Lasker Award for Basic Medical Research (2000), the Michael Landau Prize for Life Sciences (2001), the EMET prize (2002), and the Israel Prize in biology (2003). Professor Ciechanover is a member of many academies of science, among which are the Israel Academy of Sciences and Humanities, and the National Academies of Sciences, Engineering, and Medicine (United States). Professor Ciechanover lives in Haifa, Israel. He is married to Dr. Menucha Ciechanover and father of Itzchak (Tzachi).

*aaroncie@technion.ac.il 